\title{
Optimum Contracts for Research Personnel, Research Employment, and the Establishment of "Rival" Enterprises
}

\section{Citation}

Pakes, Ariel, and Shmuel Nitzan. 1983. Optimum contracts for research personnel, research employment, and the establishment of "rival" enterprises. Journal of Labor Economics 1(4): 345-365.

\section{Published Version}

http://www.jstor.org/stable/2534859

\section{Permanent link}

http://nrs.harvard.edu/urn-3:HUL.InstRepos:3428538

\section{Terms of Use}

This article was downloaded from Harvard University's DASH repository, and is made available under the terms and conditions applicable to Other Posted Material, as set forth at http:// nrs.harvard.edu/urn-3:HUL.InstRepos:dash.current.terms-of-use\#LAA

\section{Share Your Story}

The Harvard community has made this article openly available.

Please share how this access benefits you. Submit a story.

\section{Accessibility}




\section{CHICAGO JOURNALS}

\section{National Opinion Research Center}

Optimum Contracts for Research Personnel, Research Employment, and the Establishment of "Rival" Enterprises

Author(s): Ariel Pakes and Shmuel Nitzan

Source: Journal of Labor Economics, Vol. 1, No. 4 (Oct., 1983), pp. 345-365

Published by: The University of Chicago Press on behalf of the Society of Labor Economists

and the National Opinion Research Center.

Stable URL: http://www.jstor.org/stable/2534859

Accessed: 04/12/2009 15:44

Your use of the JSTOR archive indicates your acceptance of JSTOR's Terms and Conditions of Use, available at http://www.jstor.org/page/info/about/policies/terms.jsp. JSTOR's Terms and Conditions of Use provides, in part, that unless you have obtained prior permission, you may not download an entire issue of a journal or multiple copies of articles, and you may use content in the JSTOR archive only for your personal, non-commercial use.

Please contact the publisher regarding any further use of this work. Publisher contact information may be obtained at http://www.jstor.org/action/showPublisher?publisherCode=ucpress.

Each copy of any part of a JSTOR transmission must contain the same copyright notice that appears on the screen or printed page of such transmission.

JSTOR is a not-for-profit service that helps scholars, researchers, and students discover, use, and build upon a wide range of content in a trusted digital archive. We use information technology and tools to increase productivity and facilitate new forms of scholarship. For more information about JSTOR, please contact support@jstor.org. 


\title{
Optimum Contracts for Research Personnel, Research Employment, and the Establishment of "Rival" Enterprises
}

\author{
Ariél Pakes, Hebrew University of Jerusalem and the Falk \\ Institute
}

Shmuel Nitzan, Hebrew University of Jerusalem

This paper considers the problem of hiring scientists for research and development projects when one takes explicit account of the fact that the scientist may be able to use the information acquired during the project in a rival enterprise. Management's problem is to determine an optimum labor policy for its project. The policy consists of an employment decision and a labor contract. Given optimum behavior, it is straightforward to analyze the effect of the potential for mobility of scientific personnel on project profitability and on research employment. We also formalize conditions under which one would expect to observe a scientist leaving his employer to set up or join a rival.

However, no amount of legal protection can make a thoroughly appropriable commodity of something so intangible as information. The very use of information in any productive way is bound to reveal it, at least in

We are indebted to Morris Teubal and two referees for their insights into the problems discussed here, and to the participants in seminars at the Hebrew University, the National Bureau of Economic Research, the University of Toronto, and the University of Chicago for their comments. Ariél Pakes acknowledges the financial assistance of BSF grant 1881/79 and NSF grant PRA79-13740 and SOC7804279. 
part. Mobility of personnel among firms provides a way of spreading information. [Arrow (1962), p. 615]

At least since the work of Schumpeter (1942), economists have stressed the fact that the private rate of return to research resources (and hence research employment) is determined, in part, by the degree to which a firm can maintain proprietary rights (monopoly power) over the information produced in its research laboratories. Given the rapid increase in industrial research expenditure since World War II and the increasingly convincing empirical evidence on their impact, it is a bit disconcerting that so little work has been done on how firms facing this appropriability problem ought to behave. That is, how should a firm act in order to protect its innovations? How does the action it takes affect research demand and the structure of science-based industry?

One frequently cited mechanism for the spread of the information produced in industrial research laboratories is the mobility of scientific personnel. It is not a difficult mechanism to explain. Research projects often require a good idea and substantial investments before they produce an output which can be embodied in a marketable good or service. The output of the project is a new piece of information which has no (or a very low) cost of reproduction; and any scientist working on the project is likely to be at least as aware of this information as the management. The scientist can therefore wait until the information has been developed and then decide to leave and use it in a rival enterprise. Indeed (as will be discussed below), there are many well-documented cases of scientists leaving their employers to set up or join a rival.

The purpose of this paper is to investigate the effects of the mobility of scientific personnel on project profitability, research employment, and the structure of science-based industry. A simple framework capable of analyzing these issues is provided in Section I. We begin with an entrepreneur who has an idea which could lead to a successful innovation. There is no (or a very imperfect) market for the idea as such, and in order to profit from it, the entrepreneur finds it in his interest to hire a scientist to help develop the idea into a marketable output. The entire project takes two periods. At the end of the first period the random outcome of the research stage of the project is known with certainty. The second period is used to market the project's output.

The entrepreneur's problem is to determine an optimal labor policy for the project that takes explicit account of the fact that at the end of the first period the scientist will have the option of leaving to join a rival. The labor policy consists of an employment decision (the quality of the scientist to hire) and a labor contract. This problem is a particular example of the principal's problem in the theory of agency (for a general description of the principal's problem, see Ross [1973]). There is a growing 
literature in labor economics on the characteristics of optimal labor contracts in an assortment of environments (related references are provided in the text). To focus on those aspects of our problem that are a direct consequence of the mobility of scientific personnel, we assume risk neutrality, scientists of known qualities, an absence of other sources of uncertainty (other than that involved in the research project), and that the effort the scientist devotes to the project is independent of the terms of the contract. The contract must, however, control, to the extent profitable, the mobility of the scientist in the second period (a problem related to Becker and Stigler's [1974] discussion of appropriate compensation schemes for law enforcers when malfeasance is possible; see also Harris and Raviv [1978] and Lazear[1979]). We develop the conditions that an optimal contract must satisfy (and consider the type of contractual agreements that are likely to satisfy them); the implications of the potential for mobility of scientific personnel both on project profitability and on research employment; and the conditions under which optimal behavior by all agents can result in the scientist's actually leaving in the second period to set up (or join) a rival.

Sections II and III differ in the assumptions made on the economics of the research and marketing process. Due to this difference the model of Section III can generate situations where optimal behavior by all agents does lead to the establishment of a rival, while the model of Section II cannot. The Appendix provides formal proofs for arguments made in the text, and the paper concludes with a short summary.

\section{The Basic Framework}

Consider an entrepreneur with an idea which could lead to a successful innovation. There is no (or a very imperfect) market for the idea as such, and to profit from it fully the entrepreneur must develop the idea into a marketable output. This in turn requires the commitment of resources to a research project (and, if the project is successful, to production and marketing). In particular, because there are costs of acquiring skills and a premium on time (lest someone else develop an innovation which renders the entrepreneur's idea obsolete), it is in the entrepreneur's interest to hire a scientist. Initially assume that the only costly resource employed in the research project is this scientist. The outcome of the research project will be known after a single period. The period after the research is completed (the second period) will be used to market its output. At the end of the research project the scientist will possess information which enables him, if he so desires, to market the new information himself. As a result, the entrepreneur realizes that no matter what the project's technical outcome, at least two different market situations could arise. If the scientist does not leave the firm to set up (or join) a rival enterprise, the entrepreneur's firm may monopolize the information that resulted from 
the project. Alternatively, if the scientist sets up a rival, there will be at least two firms with the information. In this section we assume that these are the only two market situations that can arise. That is, either a single firm or two rivals will market the output from the project.

The entrepreneur's objective is to maximize the expected profits from the project. He can choose the skill level, say $s$, of the scientist he will employ. Given $s$, a series of exogenous events (associated with the realization of a particular state of nature) will determine the project's outcome. Let $\epsilon \in R$ ( $R$ is the set of real numbers) be a random variable indicating the possible states of nature and denote by $G(\epsilon)$ the distribution function which embodies the entrepreneur's prior beliefs about the likelihood of the alternative states of nature. For any $\epsilon \in R$ let $f(\epsilon, s)$ be the net revenues to be generated by the project, when the scientist chosen has skill level $s$ and if he does not set up a rival after the project is completed. We assume that $f(\epsilon, s)$ is finite and nonnegative for all $\epsilon$ and s. ${ }^{1}$ A scientist who does not set up a rival has two alternatives. He can either stay with the firm or return to the labor market to engage in some other activity. To simplify the analysis, we assume that if he should decide to stay with the firm during the second period the entrepreneur can always employ him in some other activity in which his marginal productivity equals his alternative wage. ${ }^{2}$ If, on the other hand, the scientist does set up (or join) a rival, let the entrepreneur's net revenues be $f(\epsilon, s)-$ $l(\epsilon, s)$, where $l(\epsilon, s)$, the loss due to the establishment of the rival, is assumed to be nonnegative and finite for all $\epsilon$ and $s$.

In order to hire a scientist, management specifies a labor contract, which is assumed to consist of a flat wage, $w_{0}(s)$, to be paid before the realization of $\epsilon$ and a bonus payment, $w_{1}(\epsilon, s)$, which is paid in the second period and therefore need only be paid if the scientist decides to stay with the firm. Thus, for any $s$, a labor contract is a couple consisting of a number, $w_{0}(s)$, and a random function, $w_{1}(\epsilon, s)$. The choice of the triple $\left\{s, w_{0}(s)\right.$, $\left.w_{1}(\epsilon, s)\right\}$ is referred to as a labor policy.

Consider now the behavior of scientists of different skill levels. The wages they can receive in alternative places of employment are set by the labor market and are an increasing function of their skill. We normalize $s$ so that it equals these alternative wages and assume $s \in[0, \bar{s}]=U$. It

1 That is, if the net revenues to be generated from marketing the output were expected to be negative, the firm would simply not market that output. Note that "net revenues" is used to denote the sales minus the costs incurred during the marketing period. "Profits" refers to these net revenues minus the costs of the research project.

${ }^{2}$ A similar assumption (constant marginal productivity over time) is used in most of the literature on labor turnover and quits; see the discussion in Nickell (1976) or in Salop and Salop (1976). It simplifies the analysis considerably by allowing one to abstract from the effect of possible changes in the future demand for employees on current employment decisions. 
is assumed that scientists choose their place of employment by maximizing a utility function which is linear in the money income they receive, that is, scientists are expected-payment maximizers (risk aversion is discussed briefly below). A scientist who becomes interested in the project is on inquiry informed of the terms of the contract. These terms include the probability of distribution of the bonus-that is, of $w_{1}(\epsilon, s)$ or, as would seem more likely, that of $f(\epsilon, s)$ and its relationship to $w_{1}(\epsilon, s)$ (see the next section); ${ }^{3}$ they also include the stipulation that the bonus will be paid only if the scientist decides to stay with the firm during the second period. The scientist is aware that by joining the project he will acquire information of potential value, and he realizes that it may not be in his interest to stay for both periods. If he does in fact join, he will face three alternatives at the end of the first period. He can stay and obtain the bonus, $w_{1}(\epsilon, s)$. Alternatively, he can try to capitalize on the information he has acquired by setting up or joining a rival. To evaluate this possibility, the scientist uses his knowledge of science-based industry and the information he has been given on the project to compute the possible payoffs from using the information he has acquired on the project in a rival enterprise, say $p(\epsilon, s)$. Assume that if the scientist does join (or set up) a rival he receives $p(\epsilon, s)$ plus the market value of his labor during the second period $s$. (All that is required is for the amount the scientist earns in a rival to be less than or equal to $p(\epsilon, s)+s$.) Finally, deciding that neither of these alternatives is particularly attractive, the scientist may return to the labor market to engage in another activity and earn the going rate on his skill level, $s$. Being an expected-payment maximizer, he will accept the bonus and stay with the firm if $\epsilon \in A=\left\{\epsilon \mid w_{1}(\epsilon, s) \geqslant \max [p(\epsilon, s)+s, s]\right\}$. He will quit to set up a rival if $\epsilon \in Q=\left\{\epsilon \mid p(\epsilon, s)+s>\max \left[w_{1}(\epsilon, s), s\right]\right\}$;

${ }^{3}$ Thus, if the distribution of $w_{1}(\epsilon, s)$ is approximately normal, the scientist is told so and provided with its mean and variance. In a broader framework one would also ask whether the entrepreneur could, by providing the scientist with the wrong distribution function, increase expected profits. It can be shown that, provided the scientist does not have sufficient information on the distribution of $f(\epsilon, s)$ from other sources (say, from the stock market or from a community of people involved in science-based industry who have considered similar projects in the past), and provided nothing else in the problem changes as a result of the entrepreneur's actions, the entrepreneur could increase his expected profits by persuading the scientist of an overly optimistic distribution function (see Sec. III). In this case, however, the other aspects of the problem are likely to change. In particular, the entrepreneur is likely to want to hire additional scientists later, and they are not likely to believe in an entrepreneur who has cheated before. Moreover, the scientist may realize that he has been cheated early on in the project and leave before its completion. Similar issues arise in much of the literature on labor contracts (see, e.g., Lazear 1979) and in this section we assume, as is customary, that the considerations outlined above induce the entrepreneur to reveal the correct information. A deeper analysis of this issue may, however, be warranted. 
and if $\epsilon \in R-A-Q$ he will return to the labor market. ${ }^{4}$ Clearly, then, a scientist of skill level $s$ will accept the offer to join the project only if $w_{0}(s)+{ }_{A} \int w_{1}(\epsilon, s) d G+{ }_{Q} \int[p(\epsilon, s)+s] d G+{ }_{R-A-Q} \int s d G \geqslant 2 s$, that is, if the expected payments from joining the project are at least equal to the payments he would receive over the two periods in alternative employment (for simplicity we shall ignore discount factors).

The economic structure of the problem set out in this section suggests one more constraint (Sec. III differs in this respect). If the scientist's evaluation of $p(\epsilon, s)$ and the entrepreneur's beliefs on $l(\epsilon, s)$ are at all close to the gains the scientist would actually make from setting up a rival and the entrepreneur's consequent losses, respectively, we would expect $p(\epsilon, s)-l(\epsilon, s) \leqslant 0$, for all $\epsilon \in R$. The difference between $p(\epsilon, s)$ and $l(\epsilon, s)$ is likely to be a result of two factors: the additional costs incurred if a rival is set up, and the fact that postproject competitive behavior is likely to divert to consumers some of the gains that would otherwise accrue to the monopolist. Thus, the sum of the gains that would accrue to the two agents in a situation involving rivalry could never exceed those that would accrue in the monopolistic situation. This would be true even if neither of them incurs any additional costs as a result of the rival appearing. The rival, however, is likely to incur some startup costs; and in situations involving rivalry, both agents may incur additional costs due to product differentiation and advertising. Although, as we show in the next section, the condition that $p(\epsilon, s)-l(\epsilon, s) \leqslant 0$ is sufficient for our purposes, we begin by restricting the problem further and assuming that $l(\epsilon, s)=\alpha f(\epsilon, s)$ for $0 \leqslant \alpha \leqslant 1$, and $p(\epsilon, s)=\alpha f(\epsilon, s)-c(s)$. Here, if the scientist sets up a rival, the entrepreneur loses a fraction $\alpha$ of the net revenues that he would otherwise have obtained. The scientist, on setting up or joining a rival, gains all these net revenues but must incur setup costs, $c(s) \geqslant 0$.

We can now formalize the entrepreneur's expected-profit-maximization problem.

\section{Problem A}

$$
\begin{aligned}
\max _{\left\{s \in U, w_{0}(s), w_{1}(\epsilon, s)\right\}}={ }_{R} \int f(\epsilon, s) d G- & w_{0}(s) \\
& -{ }_{A} \int\left[w_{1}(\epsilon, s)-s\right] d G-{ }_{\mathrm{Q}} \int \alpha f(\epsilon, s) d G,
\end{aligned}
$$

where $A=\left\{\epsilon \mid w_{1}(\epsilon, s) \geqslant \max [\alpha f(\epsilon, s)-c(s)+s, s]\right\}$ and $Q=\{\epsilon \mid \alpha f(\epsilon, s)-$

${ }^{4}$ Let $B$ and $C$ be two sets. To simplify the notation we denote the union of $B$ and $C$ when $B$ and $C$ are disjoint by $B+C$ and the set of all elements in $B$ which are not contained in $C$ by $B-C$. 
$\left.c(s)+s>\max \left[w_{1}(\epsilon, s), s\right]\right\}$, subject to

$$
\begin{aligned}
2 s \leqslant w_{0}(s) & +{ }_{A} \int w_{1}(\epsilon, s) d G \\
& +{ }_{Q} \int[\alpha f(\epsilon, s)-c(s)+s] d G+{ }_{R-A-Q} \int s d G .
\end{aligned}
$$

We shall impose the usual regularity conditions on $f(\epsilon, s)$.' That is, for each $\epsilon, f(\epsilon, s)$ will be assumed to be increasing and concave in $s$ $\left[f_{s}^{\prime}(\epsilon, s)>0, f_{s s}^{\prime \prime}(\epsilon, s)<0\right]$, while $f_{s s}^{\prime \prime}(\epsilon, s)$ is assumed to be bounded. (The regularity conditions are required for the existence of a unique optimum $s$, but not for our derivation of the optimum contract.)

\section{Optimum Labor Policies}

Semiconductor firms attract and reward valuable employees not so much by offering high salaries as by giving stock options. [Braun and MacDonald (1978), p. 132]

Proposition 1 and the explanation which follows it provide the solution to problem A. (The App. gathers the formal proofs for the propositions and corollaries presented in the text.)

PROPOSITION 1: Any labor policy consisting of a contract, $\left\{w_{0}(s)\right.$, $\left.w_{1}(\epsilon, s)\right\}$, satisfying $w_{1}(\epsilon, s) \geqslant \alpha f(\epsilon, s)-c(s)+s$, for all $\epsilon \in A^{*}=\{\epsilon \mid$ $\alpha f(\epsilon, s)-c(s) \geqslant 0\}$, and $w_{0}(s)=s-{ }_{A} \int\left[w_{1}(\epsilon, s)-s\right] d G$; and the unique skill level $s^{*}$ which satisfies ${ }_{R} \int f_{s}^{\prime}\left(\epsilon, s^{*}\right) d G=1$ (if no such $s^{*} \in U$ exists, then the optimum $s$ is at one of the boundaries, 0 or $\bar{s})$; is a solution for problem A.

The knowledge that initiates the project (and that the scientist acquires by virtue of joining) generates two random variables: the value of the knowledge to the entrepreneur, and its value to the scientist. The realizations of these random variables are determined both by the outcome of the research (i.e., by $\epsilon$ ) and by the scientist's action in the second period. For any $\epsilon$ in which the sum of the two values is at least as large if the project's output is utilized in a single firm-that is, for which $p(\epsilon, s)<l(\epsilon, s)$ - the entrepreneur can always pay the scientist as much as the scientist would earn in a rival and still earn more than the entrepreneur would earn if the rival were set up. (These are outcomes in which the knowledge becomes capital with characteristics similar to those of firm-specific human capital as defined by Becker [1975]). ${ }^{5}$ Since problem A assumes that such outcomes occur with probability 1, contracts which are optimal for it must always deter the scientist from setting up a rival.

${ }^{5}$ The difference is that we are dealing with a type of capital that is not embodied in the scientist (the scientist need not actually use it in the second period for either agent to earn returns). 
If we note that $A^{*}$ is the set of all $\epsilon$ for which the scientist would actually set up a rival were he to leave (instead of engage in some other activity), it follows that an optimal contract must have $w_{1}(\epsilon, s) \geqslant \alpha f(\epsilon, s)-c(s)$ $+s$ for $\epsilon \in A^{*}$ (this condition ensures that $Q^{*}=\emptyset$, the null set). Given this condition and any $s$, the entrepreneur is interested in minimizing the expected payments to the scientist subject to the constraint that these payments must be sufficient to draw a scientist of quality $s$ to the job (condition [1]). Substituting $Q^{*}=\emptyset$ into (1), this argument sets the initial wage at $w_{0}(s)=s-{ }_{A} \int\left[w_{1}(\epsilon, s)-s\right] d G$. The scientist's initial wage is set lower than his alternative wage by an amount just equal to the premium over the alternative wage the scientist can expect to earn in the second period. Optimal contracts for problem A are therefore similar to the bond-pension schemes discussed in several places in the literature on labor contracts (see the references in n. 8); with the difference that a "pension" $\left[w_{1}(\epsilon, s)\right]$ which satisfies proposition 1 is a random variable whose realization depends on the fortunes of the firm. Finally, substituting $Q^{*}=$ $\emptyset$ and the optimal $w_{0}(s)$ into the profit function, it is clear that the only problem left to an optimizing entrepreneur is to choose an $s \in U$ to maximize $_{R} \int f(\epsilon, s) d G-s$. Clearly $s^{*}$, as defined in the proposition, solves this problem. Corollary 1.1 is an immediate consequence of proposition 1.

Corollary 1.1: The labor policy consisting of $s^{*}$, and the contract $w_{1}^{*}(\epsilon, s)=\max \{\alpha f(\epsilon, s)-c(s)+s, s\}$, for all $\epsilon \in R$, and $w_{0}^{*}(s)=s-$ ${ }_{R} \int\left[w_{i}^{*}(\epsilon, s)-s\right] d G=s-{ }_{A} \int[\alpha f(\epsilon, s)-c(s)] d G$, is optimal for problem A.

Of the contracts satisfying proposition 1 , we emphasize $\left\{w_{0}^{*}(s), w_{i}^{*}(\epsilon\right.$, s)\} for two reasons; first, it is exceedingly easy to implement. The hiring agreement need only specify that during the second period the scientist will be offered, in addition to his alternative wage, a stock option. The stock option specifies that if the scientist decides to stay with the firm in the second period he will be allowed to purchase, at a cost of $c(s)$, a fraction $\alpha$ of the firm's equity. ${ }^{6}$ Of course the offer of a profit-sharing scheme of the form $w_{1}(\epsilon, s)=\beta f(\epsilon, s)+s$, with $\beta \geqslant \max _{\epsilon \in R}\{[\alpha f(\epsilon, s)$ $-c(s)] / f(\epsilon, s)\}$ and with $w_{0}(s)$ as defined in the corollary, will do equally well. In fact, a stock option (or profit-sharing) scheme of this form will be optimal for arbitrary gain, $p(\epsilon, s)$, and loss, $l(\epsilon, s)$, functions provided that $\beta \geqslant \max _{\epsilon \in R}\{p(\epsilon, s) / f(\epsilon, s)\}$. ${ }^{7}$ The second, and perhaps more important,

${ }^{6}$ This, of course, assumes that the project is financed by the issue of equity and that the stock market provides a reasonable approximation of the value of the project. Note that if $\alpha f(\epsilon, s)-c(s)<0$, it does not matter whether the scientist stays with the firm or engages in some other activity.

' Note that this assumes either that the scientist cannot sell the information without leaving the firm or that if this did happen the entrepreneur, whose profits would fall, could stop the payment of the bonus. If neither of these conditions is satisfied, then the entrepreneur ought to choose a contract (from those satisfying proposition 1) which ensures that it is not in the scientist's interest to both stay 
reason for emphasizing stock option agreements is that they tie the second-period payment to the scientist directly to the fortunes of the firmthat is, the realization of $\epsilon$-and to those aspects of the structure of the industry that determine the gains and losses that would result from setting up a rival-here, $\alpha$ and $c(s)$. As will be shown below, when we complicate problem A the set of optimal contracts narrows (often to a single one), but an optimal contract must always have these characteristics. These are also the characteristics that distinguish contracts designed to help solve the appropriability problem in a firm's research laboratory from contracts designed to help solve other agency problems that arise in the context of employer-employee relationships (which explains the quotation at the beginning of this section). ${ }^{8}$

Proposition 1 implies that the entrepreneur can maximize expected profits by following a simple two-stage decision procedure. First, choose $s$ to maximize expected profits, ignoring the fact that the scientist may be able to use the information he acquires on the project to set up a rival; then choose a labor contract that ensures both that a rival never appears and that the expected costs of employing the scientist just equal his alternative wage. There will always exist a particularly simple labor contract consisting of a flat rate and a profit-sharing scheme which satisfies these conditions.

These conclusions have two implications of particular interest. First, provided all agents act optimally, input decisions $(s)$ and the expected profitability of research projects are independent of the institutional, market, and technological conditions which determine the gains and the losses agents would incur if a rival were set up. Second, again provided all agents act optimally, we should not observe a scientist breaking away from an established firm to join or set up a rival. These results would not be altered if one allowed for the fact that many different factors of production are typically used in research projects (in this case, all input quantities should be chosen to maximize expected profits, ignoring the possibility that a rival will appear). ${ }^{9}$

with the firm and sell the information in the second period (the contract would then have to provide the scientist with all the net revenues in the second period apart from a sum equal to the cost of selling the information).

${ }^{8}$ The latter include monitoring on-the-job effort, the allocation of uncertainty, and the unraveling of unobserved characteristics (see, among others, Stiglitz [1975], Ackerloff [1976], Nickell [1976], Salop and Salop [1976], Mortensen [1978], Lazear [1979], and Lazear and Rosen [1981]). Though allowing for these other issues complicates the problem significantly (and this probably accounts for the at least implicit complexity of the contractual agreements that we actually observe), none of them (to our knowledge) leads to contracts with the characteristics noted above.

${ }^{9}$ In particular, the entrepreneur will never be induced to substitute any other factor for skill beyond the point where the ratio of the expected marginal products of all factors equals the ratio of their costs, regardless, of course, of whether an 
It should be noted, however, that if there are bounds on contracts or if agents have nonlinear utility functions, then the first of these implications is modified but the second need not be. It is easiest to illustrate this point by adding a nonnegativity constraint to problem A (see also n. 10 below). Note that if the project has some probability of generating large net revenues, or if $\alpha$ is large while $c(s)$ is small, then to implement an optimal contract for problem $\mathrm{A}, w_{0}(s)$ may have to be very small or negative, that is, $w_{0}(s) \leqslant s-{ }_{A} \int\{\alpha f(\epsilon, s)-c(s)\} d G$ (from proposition 1). If one adds the constraint that, due to convention or legal restrictions (minimum wage laws), $w_{0}(s)$ has to be above some minimum value (which we take for simplicity to be zero), then the potential mobility of scientific personnel can affect both project profitability and input decisions; but, provided all agents act optimally, the scientist will still never actually set up or join a rival. To see this, note that the addition of the nonnegativity constraint, $w_{0}(s) \geqslant 0$, does not alter the fact that for any $\epsilon$ the entrepreneur can always do better by deterring the scientist from setting up a rival; and this leads to the conclusion that for a contract to be optimal it must never induce the scientist to do so. ${ }^{10}$ The nonnegativity constraint will,

increase in skill decreases the cost of setting up a rival. The problem does get more complicated in situations where it may be profitable to hire more than one scientist who will (at the end of the first period) possess information that enables them to set up a rival. The reason is that the gains any one of the scientists would make from setting up a rival may, in this case, depend on the behavior of the others. Provided the total gains from setting up a rival are always less than the entrepreneur's losses and that constraints analogous to (1) continue to hold, the solution does not, however, differ substantively. The entrepreneur ought still to ensure that a rival never appears by paying each scientist a high enough bonus (say, higher than the maximum gain he could make as a result of a rival appearing) to lower the initial wage as much as possible and thus to ensure that he the entrepreneur) garners all the expected net revenues from the project other than the scientists' alternative cost. Of course, for many. (usually all but one or two) of the individuals working on a research project, these considerations are irrelevant. Most personnel do not work on tasks enabling them to gather information that would be of much value to a rival.

${ }_{10}$ The argument that, given $\epsilon$, the entrepreneur can always do better by deterring the scientist from setting up a rival does not depend on the linearity of either agent's utility function. Allowing for nonlinear utility functions, however, complicates the analysis significantly. The source of the complication is that with nonlinear utility functions there will be cases in which an optimal contract from the set of contracts considered in this paper would induce the establishment of a rival even though, because of the argument given above, there are contracts not in this set which are preferred by both agents and which do not induce the appearance of a rival. Broadening the set of feasible contracts complicates the technical formulation of the problem significantly without changing the basic thrust of the arguments presented here (which is the reason we have chosen to illustrate the points in this paragraph with the aid of the nonnegativity constraint). It should also be noted that the discussion in this paragraph assumes that the scientist cannot both receive the bonus in the second period and sell the information to a third party (see n. 7). 
however, tend to make contracts with higher initial wages and lower bonus payments preferable. The lowest bonus function that still satisfies the condition that it will never induce the appearance of a rival is given by $w_{I}^{*}(\epsilon, s)$, as defined by corollary 1.1. Given $w_{i}^{*}(\epsilon, s)$, the lowest initial wage which satisfies both the nonnegativity and feasibility conditions is $w_{0}^{+}(s)=\max \left\{0, w_{0}^{*}(s)\right\}$; and, as a result, the contract $\left\{w_{0}^{+}(s), w_{i}^{*}(\epsilon, s)\right\}$ will always constitute an optimal solution. Clearly in this (second-best) situation the appropriability problem in a firm's research laboratory can only decrease project profitability; but, and this is the interesting point, it may actually increase research employment. Consider, for example, the case where the nonnegativity constraint is binding at $\left\{s^{*}, w_{0}^{+}\left(s^{*}\right), w_{i}^{*}\right.$ $\left.\left(\epsilon, s^{*}\right)\right\}$, but the feasibility constraint (1) is not-that is, $w_{0}^{+}\left(s^{*}\right)=0>$ $w_{0}^{*}\left(s^{*}\right)$; if this were not the case the policy of corollary 1.1 could still be implemented, and would be optimal—and assume $c(s)=c$ (a constant). Since the feasibility constraint is not binding a marginal increase in skill from $s^{*}$ results in an increase in expected costs just equal to the increase in expected bonus required to ensure that a rival will not be established, and this is just a fraction, $\alpha$, of the increase in expected benefits. The entrepreneur will, therefore, be induced to increase skill beyond $s^{*}$; in fact, the same argument implies that the entrepreneur will increase skill until the expected benefits to the scientist over the two periods just equal his alternative wage. After that point, say $s^{+}$, the increase in expected costs from further increases in skill is unity, while the increase in expected benefit is ${ }_{R} \int f_{s}^{\prime}\left(\epsilon, s^{+}\right) d G$, which, since $s^{+}>s^{*}$ and $f(\cdot, \cdot)$ is concave in $s$, is less than unity. ${ }^{11}$ Finally, we stress that the conditions discussed in this paragraph ought not, in themselves, lead to scientists actually breaking away from their employer to set up rivals. Thus to find situations that may induce scientists to do so, we examine the economics of the research and marketing processes more closely.

\section{Quits and the Establishment of "Rivals"}

Mobility within the semiconductor industry has been aided by the very tolerant attitude of most firms towards movement of personnel. [Braun and MacDonald (1978), p. 135]

Though it may well be true that in most science-based industries one

${ }^{11}$ If no such $s \in U$ exists, the entrepreneur will choose the maximum value of $s$, i.e., $\bar{s}$. Formal proofs of the statements in this paragraph are provided in proposition 1A and corollary 1A of the Appendix. Barzel (1968) and Dasgupta and Stiglitz (1980) have also argued that the public-good characteristics of knowledge can lead to overinvestment in research, but in their models this result occurs because there can be many different entrepreneurs who search, simultaneously, for the innovations emanating from a given idea. The next section considers the implications of the appropriability problem in a firm's research laboratories when this can happen. 
seldom observes a scientist breaking away from his employer to set up a rival, there is at least one industry, the semiconductor industry, where this has happened quite often. ${ }^{12}$ Indeed, many studies of the structure of the semiconductor industry begin by constructing a "family tree" of firms that were offshoots from each other (see, for example, Freeman [1974], pp. 147-49). As the discussion of the last section indicates (and corollary 2.2 will formalize), to accommodate this phenomenon in our framework there must be possible outcomes in which $p(\epsilon, s)>l(\epsilon, s)$; that is, outcomes in which the scientist believes that he will gain more by setting up a rival than what the entrepreneur believes he (the entrepreneur) will lose as a result of the rival's appearance. There are, therefore, at least two questions of interest. First, when would we expect such outcomes to occur? Second, how do they affect project profitability and research employment? In this section we discuss two sets of conditions which have the potential of actually inducing the scientist to set up a rival. In both, the actions of all agents are a result of optimum behavior based on correct information. ${ }^{13}$ Moreover, these conditions are not unlike those which have developed in the semiconductor industry. Our discussion will focus on their implications for project profitability and on optimum labor policies, leaving several interesting questions concerning the environments which generate these conditions for subsequent work. In particular, it will be shown that, provided the entrepreneur uses an optimum labor contract, he need not be troubled by the possibility that scientific personnel may move. In fact, all else equal, the entrepreneur should prefer situations in which it is relatively easy for the scientist to do so.

\section{Third-Party Entrants}

Sections I and II have assumed that the entrepreneur and the scientist whom he employs jointly retain perfect monopoly power over the information produced during the research project. There are, however, several ways in which third parties might gain access to this information. The output of the project may spread as a result of inspection of either the product in which it is embodied or the patents resulting from the project (indeed, patents would not exist if there were no possibility of

${ }^{12}$ One would need a very detailed history of an industry to determine that it does not exhibit this phenomenon. On the other hand, many science-based industries seem to operate with a fairly stable number of firms; see Temin (1979) on the drug industry since World War II, Phillips (1974) on the aircraft industry, and Freeman's (1974) description of the synthetic materials industry after World War I.

${ }^{13}$ Of course, the scientist may wrongly believe that $p(\epsilon, s)>l(\epsilon, s)$; or the entrepreneur may err in his evaluation of $l(\epsilon, s)$. Provided one precisely specifies the entrepreneur's information on $p(\epsilon, s)$ in the first period, this case can be analyzed in a model similar to those developed below, and it has the same qualitative implications on project profitability and research employment. 
third-party entrants), or a third party may complete a similar research project after the leading firm. If there is a possibility of third-party entrants the entrepreneur's optimum strategy will take into account his beliefs on how third parties are likely to act (for a formal model of entrepreneurial behavior in a related context, see Gaskins [1971]). This optimum strategy will include a labor policy. Clearly, however, if there are potential third-party entrants, the logic that led us to the optimum labor policies of the preceding section is no longer appropriate. There the argument was that since the benefits that would accrue to the scientist from setting up a rival were smaller than the consequent losses of the firm, the entrepreneur would always devise a contract deterring the scientist from setting up the rival. If other agents have access to the information, however, then the scientist, by setting up a rival, may also be able to break into profits that would otherwise accrue to third parties. In this case, both the scientist and the entrepreneur may be able to gain, if the scientist can set up a rival.

To analyze this situation we must add some notation. Again $f(\epsilon, s)$ represents the net revenues that would accrue to the entrepreneur if the scientist did not set up a rival (given the expected behavior of third parties). If the scientist does set up a rival, the payoffs to entrepreneur, scientist, and third parties all change. For simplicity, we maintain the assumption that if the scientist does set up a rival, the entrepreneur loses a fraction $\alpha$ of the net revenues-to allow for the possibility that his revenues actually increase we permit $\alpha<0$ in this section, though we continue to refer to $\alpha f(\epsilon, s)$ as the entrepreneur's losses; and that the costs of setting up a rival are $c(s)$. Depending on the realization of $\epsilon$, on technological and market conditions, and on the oligopolistic strategies pursued by the agents, part of the losses incurred by the firm may now go to agents other than the entrepreneur and the scientist (to the third parties or to consumers); alternatively, by setting up a rival, the scientist may be able to break into the net revenues that would otherwise accrue to the third parties. Accordingly, in this section we assume that the gains that would accrue to the scientist if he set up a rival are $\alpha f(\epsilon, s)-c(s)+s+$ $r(\epsilon, s)$, where the only restriction placed on $r(\epsilon, s)$ is that it be finite for all $\in \in R$ and $s \in U$.

At the end of the first period the scientist will be induced to set up a rival if this is the best of the three alternatives available to him, that is, if $\alpha f(\epsilon, s)-c(s)+s+r(\epsilon, s)>w_{1}(\epsilon, s)$ and $\alpha f(\epsilon, s)-c(s)+s+r(\epsilon, s)$ $>s$. He will stay with the firm if the first inequality is reversed and $w_{1}(\epsilon, s) \geqslant s$, while if neither of these two conditions is met he will return to the labor market and engage in some other activity.

Given the scientist's decision rules (and assuming contracts are unbounded), the entrepreneur's expected profit-maximization problem is given by problem $\mathrm{B}$. 


\section{Problem B}

$$
\begin{aligned}
\max _{\left\{s \in U, w_{0}(s), w_{1}(\epsilon, s)\right\}}={ }_{R} \int f(\epsilon, s) d G- & w_{0}(s) \\
& -{ }_{A_{r}} \int\left[w_{1}(\epsilon, s)-s\right] d G-{ }_{\mathrm{Q}} \int \alpha f(\epsilon, s) d G,
\end{aligned}
$$

where $A_{r}=\left\{\epsilon \mid w_{1}(\epsilon, s) \geqslant \max [\alpha f(\epsilon, s)-c(s)+s+r(\epsilon, s), s]\right\}$ and $Q_{r}$ $=\left\{\epsilon \mid \alpha f(\epsilon, s)-c(s)+s+r(\epsilon, s)>\max \left[w_{1}(\epsilon, s), s\right]\right\}$, subject to

$$
\begin{aligned}
2 s \leqslant w_{0}(s) & +{ }_{A r} \int w_{1}(\epsilon, s) d G \\
& +{ }_{Q} \int[\alpha f(\epsilon, s)-c(s)+s+r(\epsilon, s)] d G+{ }_{R-A_{r}-Q_{r}} \int s d G .
\end{aligned}
$$

Proposition 2 provides the optimal contract for problem B.

Proposition 2: Regardless of the choice of $s$, an optimum labor contract for problem B is $w_{1}^{r}(\epsilon, s)=\max \{\alpha f(\epsilon, s)+s, s\}, w_{0}^{r}(s)=s-$ ${ }_{R} \int\{\max [\alpha f(\epsilon, s), 0]\} d G-{ }_{Q} \int[r(\epsilon, s)-c(s)] d G$; where $Q_{r}^{*}=\{\epsilon \mid r(\epsilon, s)$ $-c(s)>0$ and $\alpha f(\epsilon, s)-c(s)+r(\epsilon, s)>0\}$.

The bonus scheme, $w_{1}^{r}(\epsilon, s)$, is implemented by the entrepreneur offering the scientist a profit-sharing agreement plus his alternative wage. The share is the fraction of the firm's net revenues the scientist would take away if the scientist were to set up a rival. The scientist only accepts the profit-sharing agreement if $\alpha f(\epsilon, s)>0$. To see why this bonus scheme is optimal, note that, since the scientist can always return to the labor market to engage in some other activity, the scientist will not set up a rival unless $\alpha f(\epsilon, s)-c(s)+r(\epsilon, s)>0$. Now consider those realizations of $\epsilon$ where this condition is satisfied. If $\alpha f(\epsilon, s)-c(s)+r(\epsilon, s)>$ $\alpha f(\epsilon, s)$, the entrepreneur would have to pay the scientist more to induce him to stay than the entrepreneur would lose if the scientist set up a rival. For those realizations of $\epsilon$, then, it will pay the entrepreneur to allow the employee to leave. The set $Q_{r}^{*}$ of proposition 2 is defined as the set of all $\epsilon$ in which the last two inequalities are met, and the bonus scheme $w_{1}^{r}(\epsilon, s)$ will induce the scientist to set up a rival if and only if $\epsilon \in Q_{r}^{*}$. The initial wage, $w_{0}^{r}(\epsilon, s)$, is the minimum flat wage acceptable (satisfying [2]), given that the scientist will receive $\alpha f(\epsilon, s)-c(s)+s+r(\epsilon, s)$ if $\epsilon$ $\epsilon Q_{r}^{*}$ and $w_{1}^{r}(\epsilon, s)$ otherwise.

To derive the optimum skill level for problem $\mathrm{B}$, we require additional assumptions on $T(s)={ }_{Q} \int[r(\epsilon, s)-c(s)] d G$, which is likely to increase in $s$, since one would expect $r_{s}^{\prime}(\epsilon, s) \geqslant 0$ and $c_{s}^{\prime}(s) \leqslant 0$. If in addition we assume that $T(s)$ is concave for all $s$, or at least not sufficiently convex to offset the concavity of ${ }_{R} \int f(\epsilon, s) d G$, and that $T_{s}^{\prime \prime}(s)$ is bounded, we have the following corollary.

COROLlaRY 2.1: If there exists an $s^{r} \in U$ which satisfies ${ }_{R} \int f_{s}^{\prime}\left(\epsilon, s^{r}\right) d G+{ }_{Q_{r}^{r}(s)} \int\left[\mathrm{r}_{s}^{\prime}\left(\epsilon, s^{r}\right)-c_{s}^{\prime}\left(s^{r}\right)\right] d G=1$, then $s^{r}$ is the optimum 
skill level for problem B. Otherwise the optimum $s$ is at one of the boundaries, 0 or $\bar{s}$.

The sum of the entrepreneur's and scientist's gains from setting up a rival is $r(\epsilon, s)-c(s)$, and $Q_{r}^{*}(s)$ is the set of all $\epsilon$ for which this sum is positive and for which the scientist, if he quits, would actually set up the rival (rather than engage in some other activity). By using a labor contract which induces the scientist to set up a rival if $\epsilon \in Q_{r}^{*}(s)$, and then setting the flat wage at the minimum acceptable given optimum behavior by the scientist, the entrepreneur ensures that his expected gain includes the maximum expected gain that could possibly arise as a result of the mobility of scientific personnel, $T(s)$. The entrepreneur will choose $s$ to maximize these gains plus ${ }_{R} \int f(\epsilon, s) d G-s$. All else equal, then, the entrepreneur ought clearly to prefer environments in which it is easier for the scientist to set up a rival and where the scientist can earn larger profits from the rival. Corollary 2.2 is an immediate consequence of the definition of $Q_{r}^{*}\left(s^{r}\right)$.

COROLlARY 2.2: Given optimum behavior of all agents, the necessary and sufficient condition for quits and the establishment of rivals to be possible is that $r\left(\epsilon, s^{r}\right)-c\left(s^{r}\right)>0$ and $\alpha f\left(\epsilon, s^{r}\right)+r\left(\epsilon, s^{r}\right)-c\left(s^{r}\right)>0$ for some $\epsilon$ with positive probability.

Thus, one should observe scientists setting up rivals when setup costs are low and when other agents (third parties) are likely to enter similar activities. Indeed, one would expect these two conditions to be mutually supportive, that is, low setup costs may induce third-party entrants, while third-party entrants may attract venture capital to the particular field of activity (see the description of the evolution of Santa Clara, or "Silicon" Valley, in Bylinsky [1976], chap. 4).

To summarize, it is clear that the inability of the firm to maintain perfect monopoly power over its discoveries may induce third-party entrants, thereby creating conditions which result in the scientist's breaking away from the entrepreneur to set up a new enterprise. Nonetheless, the mobility of scientific personnel is not, in itself, a source of concern to entrepreneurs. Indeed, an optimum labor contract ensures that the scientist will only set up a new enterprise when it would help the entrepreneur to gain some of the revenues that would otherwise accrue to third parties.

\section{Spin-Offs}

One way of stating the general result underlying the discussion of this section is that an optimum labor contract could induce the scientist to set up a rival if there are possible states of nature in which the establishment of the rival increases the sum of the returns accruing to the two agents involved in the project. The classic economic reason for total profits 
to increase when two firms (rather than one) engage in an activity is increasing costs (here interpreted to include the costs of gathering and processing information; see the review by Spence [1975] and, more recently, Rosen [1981] and Keren and Levhari [1983]). There is one characteristic of research projects which deserves emphasis in this context. Research projects, especially those in relatively young, science-based industries, often produce multiple outputs, that is, discoveries leading to several different innovations, some of which are only marginally related to the project's original goals. ${ }^{14}$ In cases with multiple discoveries, in general, there will be costs and benefits associated with the coordination of subsequent financial, development, and marketing decisions. The particular aspects of the process worth coordinating may be best served by different organizational structures (the possibilities include, in addition to the formation of a separate enterprise, the establishment of a holding company, and the setting up of separate research and production departments within a given firm); which one is economic will depend on technological, market, and (particularly when antitrust laws are a factor) institutional considerations. The analysis and implications of situations in which there exists the possibility of multiple discoveries and increasing costs is similar to that of the last subsection and therefore will not be developed here. It should be noted, however, that provided setup costs are not too high, this argument leads us to expect to observe scientists' breaking away from their employers to set up rivals when the economic possibilities embodied in the applied science being used in research projects are relatively unexplored and particularly plentiful (see the historical discussion by Rosenberg [1963, 1969]).

\section{Summary}

The basic conclusion of this paper is that the potential mobility of scientific personnel need not, in itself, have an adverse effect on project profitability. This conclusion follows from the fact that an optimizing entrepreneur who is free to choose among alternative contracts will always choose one which only induces the scientist to leave and join a rival if the sum of the benefits to the two agents increases as a result of the scientist's leaving. Contracts which specify labor payments in the form of a combination of a flat wage rate and stock option (or other profitsharing agreement) ought to be able to induce a close approximation to this behavior. Given the expected value of the profit-sharing agreement, the entrepreneur should set the initial wage, $w_{0}$, to a level which is low

${ }^{14}$ See, e.g., the discussion in Nelson (1959). Mueller's (1962) study of the origin of DuPont's major innovations lists nine of them as originating in DuPont's own laboratory and of these, two (the discoveries of teflon and $\mathrm{f}$ ducose lacquers) resulted from research accidents. 
enough to ensure that the total of the expected payments to the scientist is just equal to the scientist's alternative wage. The expected profits of an entrepreneur who follows this policy will include all the monetary gains expected to accrue to either of the two agents other than the scientist's alternative wage. That is, the entrepreneur extracts all possible rents accruing to his idea.

Clearly, then, if the sum of the benefits to the two agents cannot be increased by the scientist's leaving, the entrepreneur should specify a contract which will never induce him to do so. In this case the best the entrepreneur can do is to choose all factors to maximize the expected profitability of the research project, ignoring the possibility of quits, and then to choose a labor contract which ensures that quits will never occur. It follows that project profitability and research employment will be independent of the technological, market, and institutional factors which determine the gains the scientist would make from setting up a rival. On the other hand, if there are possible outcomes from the research project in which the sum of the monetary benefits to the two agents can be increased by the scientist leaving, the entrepreneur ought to choose a contract which will induce the scientist to leave if such an outcome materializes. In this case, the entrepreneur's expected profits will, in fact, be an increasing function of the gains the scientist could make in a rival.

We have focused on two characteristics of research projects which could lead to situations in which optimum behavior by all agents would result in the scientist breaking away from his employer to establish a rival. First, it may be possible for third parties to gain access to the information generated from the project, in which case the scientist's setting up a rival may enable the entrepreneur to recoup some of the profits that would otherwise accrue to third parties. Second, the research project may lead to several discoveries, in which case costs of coordination may result in its being economic to develop and market them in separate enterprises. In either of these cases an optimizing entrepreneur will be led to make research employment decisions to maximize all the profits to be generated by the project, whether the associated net revenues accrue to the rival or to the original firm.

In short, though we are quite sure that there are mechanisms which, because of the fact that they can be used to spread the information produced in a firm's research laboratories, reduce the profitability of research projects and (perhaps) of employment in them, the potential mobility of scientific personnel need not be one of them. The reason is straightforward. Provided the firm is free to choose among alternative labor contracts, it can provide an incentive structure which controls the mobility of the scientist-only inducing him to leave and set up a rival when it is in the firm's interest for him to do so. 


\section{Appendix}

This Appendix provides formal proofs for statements made in the text.

PROPOSITION 1: We prove that no matter the choice of $s$, a contract $\left\{w_{0}(s), w_{1}(\epsilon, s)\right\}$ will be optimal for problem A provided that $w_{1}(\epsilon, s) \geqslant$ $\alpha f(\epsilon, s)-c(s)+s$ for $\epsilon \in A^{*}$ and $w_{0}(s)=s-{ }_{A} \int\left[w_{1}(\epsilon, s)-s\right] d G$. Given this contract, the proof that $s^{*}$ is the optimal choice of $s$ follows directly from the argument given in the text.

To prove this we assume, to the contrary, that there exists an $s$, say $\tilde{s}$, and a feasible contract $\left\{\tilde{w}_{0}(\tilde{s}), \tilde{w}_{1}(\epsilon, \tilde{s})\right\}$ such that $\Pi\left\{\tilde{s}, \tilde{w}_{0}(\tilde{s}), \tilde{w}_{1}(\epsilon, \tilde{s})\right\}$ $>\Pi\left\{\tilde{s}, w_{0}(\tilde{s}), w_{1}(\epsilon, \tilde{s})\right\}$ and show that this involves a contradiction. Since $\left\{\tilde{w}_{0}(\tilde{s}), \tilde{w}_{1}(\epsilon, \tilde{s})\right\}$ must satisfy $(1) ; \tilde{w}_{0}(\tilde{s}) \geqslant 2 s-{ }_{A} \int \tilde{w}_{1}(\epsilon, s) d G-$

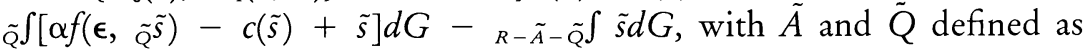
in problem A. Substituting this expression into the profit function and comparing the profits earned from this contract to those earned from $\{\tilde{s}$, $\left.w_{0}(\tilde{s}), w_{1}(\epsilon, \tilde{s})\right\}$, we find $\Pi\left\{\tilde{s}, \underline{w}_{0}(\tilde{s}), \tilde{w}_{1}(\epsilon, \tilde{s})\right\}-\Pi\left\{\tilde{s}, w_{0}(\tilde{s}), w_{1}(\epsilon, \tilde{s})\right\}=$ $-\tilde{Q} \int c(\tilde{s}) d G \leqslant 0$, which is a contradiction. Q.E.D.

Proposition $1 \mathrm{~A}$ and corollary $1.1 \mathrm{~A}$ underlie the discussion in the last paragraph of Section II.

Proposition 1A: If the constraint

$$
w_{0}(s) \geqslant 0 \text {, }
$$

is added to problem $\mathrm{A}$, then no matter the choice of $s$, the contract $\left\{w_{0}^{+}(s), w_{1}^{*}(\epsilon, s)\right\}$ is optimal, where $w_{0}^{+}(s)=\max \left\{0, w_{0}^{*}(s)\right\}$ and $\left\{w_{0}^{*}(s)\right.$, $\left.w_{1}^{*}(\epsilon, s)\right\}$ is defined by corollary 1.1 .

ProOF: We first show that for any contract $\left\{\tilde{w}_{0}(s), \tilde{w}_{1}(\epsilon, s)\right\}$ satisfying (1) and (A1) to be optimal, $\tilde{Q}$ must equal the null set. We then show that of all contracts satisfying $Q=\emptyset$ and (1)-(A1), $\left\{w_{0}^{+}(s), w_{i}^{*}(\epsilon, s)\right\}$ is an optimum. Thus consider comparing the expected profits from the contract $\left\{\tilde{w}_{0}(s), \tilde{w}_{1}(\epsilon, s)\right\}$ to those from $\left\{\hat{w}_{0}(s), w_{1}^{*}(\epsilon, s)\right\}$, where $\hat{w}_{0}(s)=\tilde{w}_{0}(s)+$ $\tilde{A} \int\left[\tilde{\mathfrak{w}}_{1}(\epsilon, s)-w_{1}^{*}(\epsilon, s)\right] d G$. Note that if $\left\{\tilde{w}_{0}(s), \tilde{w}_{1}(\epsilon, s)\right\}$ satisfies (1)-(A1), so does $\left\{\hat{w}_{0}(s), w_{i}^{*}(\epsilon, s)\right\}$. On direct substitution into the profit function we have $\Pi\left\{s, \tilde{w}_{0}(s), \tilde{w}_{1}(\epsilon, s)\right\}-\Pi\left\{s, \hat{w}_{0}(s), w_{1}^{*}(\epsilon, s)\right\}=-\tilde{A}_{\tilde{A}} \int\left[w_{1}^{*}(\epsilon, s)-\right.$ $s] d G-\tilde{Q} \int \alpha f(\epsilon, s) d G+{ }_{A^{\prime \prime}} \int\left[w_{1}^{*}(\epsilon, s)-s\right] d G=-\tilde{Q} \int c(s) d G \leqslant 0$, where the last equality follows from the fact that $A^{*}=\tilde{Q}+\tilde{A}-D[D=\{\epsilon \mid$ $\epsilon \in \tilde{A}$ and $\left.\left.\epsilon \notin A^{*}\right\}\right]$, and $w_{1}^{*}(\epsilon, s)=s$ for $\epsilon \in D$. Thus we restrict our discussion to contracts which result in $Q=\emptyset$, which implies that $\tilde{w}_{1}(\epsilon$, $s)-s \geqslant \alpha f(\epsilon, s)-c(s)$ for all $\epsilon \in A^{*}$. Among these contracts the feasibility condition implies that $\tilde{w}_{0}(s) \geqslant s-{ }_{A^{*}} \int\left[\tilde{w}_{1}(\epsilon, s)-s\right] d G$, from which it follows that for given $s$ expected profits must be less than equal to the number $\Pi_{1}(s)={ }_{R} \int f(\epsilon, s) d G-s$. Note that $\Pi_{1}(s)$ would be the optimum profit if there were no nonnegativity constraint; see proposition 1 . On the other hand, since $\tilde{w}_{1}(\epsilon, s)-s \geqslant \alpha f(\epsilon, s)-c(s)$ for $\epsilon \in A^{*}$, the nonnegativity constraint implies that expected profits must be less than or equal to $\Pi_{2}(s)={ }_{R} \int f(\epsilon, s) d G-{ }_{A^{\prime \prime}} \int[\alpha f(\epsilon, s)-c(s)] d G$. The optimum profit level would be $\Pi_{2}(s)$ if there were no feasibility constraint, that is, if expected payments to the employee could be made as small as we like 
provided that $w_{0}(s) \geqslant 0$. But $\Pi\left[s, w_{0}^{+}(s), w_{1}^{*}(\epsilon, s)\right]=\min \left[\Pi_{1}(s), \Pi_{2}(s)\right]$. Q.E.D.

COROLlary 1.1A: Let $s^{+}$be the optimal value of $s$ for problem A when the nonnegativity constraint (A1) is added, and assume $c(s)=c \geqslant$ 0 . Note that for $s \geqslant s^{*}, w_{0}^{*}(s)$ is a monotonic increasing function of $s$. Given this fact, $s^{+}$is defined as follows. If $w_{0}^{*}\left(s^{*}\right) \geqslant 0$, which implies that the nonnegativity constraint is not binding at $s^{*}$, then $s^{+}=s^{*}$; if $w_{0}^{*}(\bar{s})<0$, which implies that there does not exist an $s \in\left(s^{*}, \bar{s}\right]$ that satisfies $w_{0}^{*}(s) \geqslant 0$, then $s^{+}=\bar{s}$; and if $w_{0}^{*}\left(s^{*}\right)<0$ while $w_{0}^{*}(\bar{s}) \geqslant 0$, then $s^{+}$is the unique value of $s \in\left(s^{*}, \bar{s}\right]$ that satisfies $w_{0}^{*}\left(s^{+}\right)=0$.

PROOF: From proposition $\mathrm{A}, s^{+}$is that value of $s$ which satisfies $\max _{s \in U}\left\{\min \left[\Pi_{1}(s), \Pi_{2}(s)\right]\right\}$. Note that $w_{0}^{*}(s)=\Pi_{2}(s)-\Pi_{1}(s)$ and that $\Pi_{2}^{\prime}(s) \geqslant 0$ for all $s \in U$, while $\Pi_{1}(s)$ is concave and has a maximum at $s^{*}$. Thus, if $w_{0}^{*}\left(s^{*}\right) \geqslant 0, \Pi_{1}\left(s^{*}\right)$ is attainable, $\leqslant \Pi_{2}\left(s^{*}\right)$, and since $\Pi_{1}\left(s^{*}\right) \geqslant$ $\Pi_{1}(s)$ for all $s \in U, s^{+}=s^{*}$. If $w_{0}^{*}\left(s^{*}\right)<0$ while $w_{0}^{*}(\bar{s})>0$, then, since $w_{0}^{* \prime}(s)>0$ for all $s \in(s, \bar{s}]$, there exists a unique $s$, say $\hat{s} \in\left(s^{*}, \bar{s}\right]$, with $w_{0}^{*}(\hat{s})=0$. For $s \geqslant \hat{s}, \Pi_{1}(s) \leqslant \Pi_{1}(\hat{s})$, while for $s \leqslant \hat{s}, \Pi_{2}(s) \leqslant \Pi_{2}(\hat{s})$, which proves that in this case $s^{+}=\hat{s}$. Finally, if $w_{0}^{*}(\bar{s})<0$, then $\Pi_{2}(\bar{s})$ is attainable, $\leqslant \Pi_{1}(\bar{s})$, and since $\Pi_{2}(\bar{s}) \geqslant \Pi_{2}(s)$ for all $s \in U, s^{+}=\bar{s}$. Q.E.D.

Recall that proposition 2 and corollary 2.1 provide the optimal contract and the optimal skill level for problem B.

PROPOSITION 2: To prove this proposition we assume, to the contrary, that there exists an $s$, say $\tilde{s}$, and a feasible contract $\left\{\tilde{w}_{0}(\tilde{s}), \tilde{w}_{1}(\epsilon, \tilde{s})\right\}$ such that $\Pi\left\{\tilde{s}, \tilde{w}_{0}(\tilde{s}), \tilde{w}_{1}(\epsilon, \tilde{s})\right\}>\Pi\left\{\tilde{s}, w_{0}^{r}(\tilde{s}), w_{1}^{r}(\epsilon, \tilde{s})\right\}$, and then show that this involves a contradiction. Since $\left\{\tilde{w}_{0}(\tilde{s}), \tilde{w}_{1}(\epsilon, \tilde{s})\right\}$ must satisfy $(2), \tilde{w}_{0}(\tilde{s}) \geqslant$ $2 \tilde{s}-{ }_{A r} \int \tilde{\boldsymbol{w}}_{1}(\epsilon, \tilde{s}) d G-\tilde{Q}_{r} \int[\alpha f(\epsilon, \tilde{s})-c(\tilde{s})+\tilde{s}+r(\epsilon, \tilde{s})] d G-$ $R-\tilde{A}_{r}-\tilde{Q}_{r} \int \tilde{s} d G$ where $\tilde{Q}_{r}=\left\{\epsilon \mid \alpha f(\epsilon, \tilde{s})-c(\tilde{s})+\tilde{s}+r(\epsilon, \tilde{s})>\max \left[\tilde{w}_{1}(\epsilon\right.\right.$, $\tilde{s}), \tilde{s}]\}$. Substituting this condition and the optimum labor contract into the definition of $\Pi$ we have $\Pi\left\{\tilde{s}, \tilde{w}_{0}(\tilde{s}), \tilde{w}_{1}(\epsilon, \tilde{s})\right\}-\Pi\left\{\tilde{s}, w_{0}^{r}(\tilde{s}), w_{1}^{r}(\epsilon, \tilde{s})\right\}$ $\leqslant \tilde{Q}_{r} \int[r(\epsilon, \tilde{s})-c(\tilde{s})] d G-{ }_{\mathrm{Q}^{\prime}} \int[r(\epsilon, \tilde{s})-c(\tilde{s})] d G \leqslant 0$, a contradiction. To prove the last inequality, let $\Omega$ be the set of all subsets of the set $M=$ $\{\epsilon \mid \alpha f(\epsilon, \tilde{s})-c(\tilde{s})+r(\epsilon, \tilde{s}) \geqslant 0\}$. Clearly, $Q_{r}^{*}, \tilde{Q}_{r}, \subset \Omega$, and $Q_{r}^{*}$ maximizes ${ }_{\mathrm{Q}} \int[r(\epsilon, \tilde{s})-c(\tilde{s})] d G($ over $Q \subset \Omega)$. Q.E.D.

COROllary 2.1: To prove this corollary, substitute the optimal contract, $\left\{w_{0}^{r}(s), w_{1}^{r}(\epsilon, s)\right\}$, into the profit function for problem B to obtain $\Pi(s)={ }_{R} \int f(\epsilon, s) d G-s+{ }_{Q_{r}^{*}(s)} \int[r(\epsilon, s)-c(s)] d G$. Taking the derivative of this expression with respect to $s$ and setting it equal to zero, one obtains $s^{r}$ as defined in the corollary. ${ }^{15}$

\section{References}

Ackerloff, George. "The Economics of Caste and of the Rat Race and Other Woeful Tales.” Quarterly Journal of Economics 90 (November 1976): 599-617.

15 To see this partition $Q_{r}^{*}(s)$ into $J$ subsets, that is $Q_{r}^{*}(s)=\sum_{j=1}^{J} q_{j}(s)$, where $q_{j}(s)=\left\{\epsilon \mid \kappa_{0 j}(s)<\epsilon<\kappa_{j}(s)\right\}$. Then $\Pi(s)={ }_{R} \int f(\epsilon, s) d G-s+\sum_{j=1}^{J} \int_{\kappa \circ j(s)}^{\kappa /(s)}[r(\epsilon, s)-$ $c(s)] d G$. Noting that the value of the integrand at both its upper and lower limits for each of the $J$ groups is zero, we obtain the derivative in the corollary (see Kolmogorov and Fomin 1970, section 31.3). 
Arrow, Kenneth J. "Economic Welfare and the Allocation of Resources for Invention." In The Rate and Direction of Inventive Activity: Economic and Social Factors, edited by R. R. Nelson. Universities-National Bureau Conference Series no. 13. Princeton, N.J. : Princeton University Press (for NBER), 1962.

Barzel, Yoram. "Optimal Timing of Innovations." Review of Economics and Statistics 5 (August 1968): 348-55.

Becker, G. S. Human Capital. 2d ed. Human Behavior and Social Institutions no. 5. New York and London: Columbia University Press (for NBER), 1975.

Becker, G. S., and Stigler, George J. "Law Enforcement, Malfeasance, and Compensation of Enforcers." Journal of Legal Studies 3 (January 1974): 1-18.

Braun, Ernest, and MacDonald, Stuart. Revolution in Miniature: The History and Impact of Semiconductor Electronics. Cambridge: Cambridge University Press, 1978.

Bylinsky, Gene. The Innovation Millionaires: How They Succeed. New York: Scribner's, 1976.

Dasgupta, Partha, and Stiglitz, Joseph. "Uncertainty, Industrial Structure, and the Speed of R \& D." Bell Journal of Economics 11 (Spring 1980): 1-28.

Freeman, Christopher. The Economics of Industrial Innovation. Harmondsworth: Penguin Books, 1974.

Gaskins, Darius W., Jr. "Dynamic Limit Pricing: Optimal Pricing under Threat of Entry." Journal of Economic Theory 3 (September 1971): 306-22.

Harris, Milton, and Raviv, Artur. "Some Results on Incentive Contracts with Applications to Education and Employment, Health Insurance, and Law Enforcement." American Economic Review 68 (March 1978): 20-30.

Keren, Michael, and Levhari, David. "The Internal Organization of the Firm and the Shape of Average Costs." Bell Journal of Economics (Autumn 1983): in press.

Kolomogorov, A. N., and Fomin, S. V. Introductory Real Analysis. Rev. English ed., translated and edited by Richard A. Silverman. New York: Dover, 1970.

Lazear, Edward P. "Why Is There Mandatory Retirement?" Journal of Political Economy 87 (December 1979): 1261-84.

Lazear, Edward P., and Rosen, Sherwin. "Rank-Order Tournaments as Optimum Labor Contracts." Journal of Political Economy 89 (October 1981): 841-64.

Mortensen, Dale T. "Specific Capital and Labor Turnover." Bell Journal of Economics 9 (Autumn 1978): 572-86.

Mueller, Willard F. "The Origins of the Basic Inventions Underlying Du Pont's Major Product and Process Innovations, 1920 to 1950.” In The Rate and Direction of Inventive Activity: Economic and Social Factors, edited by R. R. Nelson. Universities-National Bureau Conference Se- 
ries no. 13. Princeton, N.J.: Princeton University Press (for NBER), 1962.

Nelson, Richard R. "The Simple Economics of Basic Scientific Research." Journal of Political Economy 67 (June 1959): 297-306.

Nickell, Steve J. "Wage Structures and Quit Rates." International Economic Review 17 (February 1976): 191-203.

Phillips, A. Technology and Market Structure: A Study of the Aircraft Industry. Lexington, Mass.: Lexington, 1974.

Rosen, Sherwin. "Output, Income and Rank in Hierarchical Firms." Economics Research Center/NORC Discussion Paper No. 81-10, University of Chicago, 1981.

Rosenberg, Nathan. "Technological Change in the Machine Tool Industry, 1840-1910.” Journal of Economic History 23 (December 1963): 414-43.

. "The Direction of Technological Change: Inducement Mechanisms and Focusing Devices." Economic Development and Cultural Change 18 (October 1969, pt.1): 1-24.

Ross, Stephen, A. "The Economic Theory of Agency: The Principal's Problem." American Economic Review, Papers and Proceedings 63 (May 1973): 134-39.

Salop, Joanne, and Salop, Steven. "Self-Selection and Turnover in the Labor Market." Quarterly Journal of Economics 90 (November 1976): 619-27.

Schumpeter, Joseph A. Capitalism, Socialism, and Democracy. 3d ed. New York: Harper, 1950. (Originally published, 1942).

Spence, A. Michael. "The Economics of Internal Organization: An Introduction." Bell Journal of Economics 6 (Spring 1975): 163-72.

Stiglitz, Joseph E. "Incentives and Risk Sharing in Sharecropping." Review of Economic Studies 51 (April 1974): 219-56.

- "Incentives, Risk and Information: Notes Towards a Theory of Hierarchy." Bell Journal of Economics 6 (Autumn 1975): 552-79.

Temin, Peter. "Technology, Regulation, and Market Structure in the Modern Pharmaceutical Industry." Bell Journal of Economics 10 (Autumn 1979): 429-46. 